\title{
Research on the Group-type of High Voltage Electric Field Measurement Safety Distance Caution Apparatus
}

\author{
Qiang Zhou ${ }^{1}$, Wei He${ }^{1}$, Songnong $\mathrm{Li}^{2}$ and Xingzhe Hou ${ }^{2}$ \\ ${ }^{1}$ Chongqing University \\ ${ }^{2}$ State Grid Chongqing Electric Power CO. Electric Power Research Institute \\ zhouqiangasd@126.com
}

\begin{abstract}
This paper introduces a kind of research and application of group-type of high voltage electric field measurement and safety distance caution apparatus based on wireless communication technology, the group-type caution apparatus is combined with a master and multiple slaves, in which the slaves are used to measure electric field and the master is used to monitor the slaves. The master keeps the real-time wireless communication with the slaves, realizing the safety dual monitoring of the high voltage working environment and guaranteeing the personnel safety of live working man. Conduct a working performance test on the site of Chongqing Rongchang 500kV Hongban transmission line I about the stability and accuracy. The test results show that the designer of group-type of $H V$ electric field measurement and safety distance caution apparatus can work stably in the strong electric field environment, besides, it has a good performance in both safety distance exceeding alarm and wireless communication.
\end{abstract}

Keywords: group-type; caution apparatus; power frequency electric field measurement

\section{Introduction}

In the power industry, electric field measurement is an effective experimental research means. With the improvement of the transmission voltage grade in our country, not only has the electric field distribution of power transmission and transformation equipment itself become a hot spot of research, but the power system electromagnetic compatibility and ecological effect of electric field problem has attracted more and more attention. Now the electric field measurement technology is not only widely used in measuring electric field strength near the high voltage transmission line or on the ground and around the substation equipment, but also provide the technical means for researchers to understand and measure the electric field distribution in the vicinity of faulty insulator, transformer winding, cable terminal, the operation of switch equipment, etc. [1-6]. Conduct actual measurements of the power frequency electric field or transient electric field around the transmission line, substation and power equipment inside by means of measurement methods, in order to obtain more valuable electric field measuring data and to provide credible data support for transmission line power equipment operation prediction, power equipment insulation condition assessment, electric power equipment design and manufacture optimization, power system operation status and electromagnetic compatibility and other fields, it has very important significance in safe and reliable operation of the entire power industry.

Domestic and foreign scholars have done a lot of research on the electric field measurement, they put forward a variety of electric field measurement method, developed various electric measuring instruments, compared with the research status abroad, both theoretical and experimental research in our country were overall behind. At the same time, it is also rare about wireless transmission technology used for electric field 
measurement, so it is necessary to study the electric field by means of wireless transmission technology.

Therefore, for high voltage transmission line workplace staffs, develop a cheap, durable, non- contact group-type of high voltage electric field measurement safety distance caution apparatus which can effectively measure and numerical visual display the high voltage transmission line electric field, and combined with the relevant provisions of national electric power industry standard, set a safety electric field threshold in each voltage grade and safety distance. When exceeding the threshold value system will alarm to the operation staff, to remind workers to keep a safe distance, preventing the electric safety accident.

The combined form adopts a master and multiple slaves. In live working, the slaves are used to measure the electric field and give an alarm when necessary, the master monitors the slaves to know the electric field and keeps the real-time wireless communication with the slaves, in case of slaves are exceeding the electric field over-limit, the master can also give an alarm. Using the group-type system can realize the dual monitoring for high voltage live working environment, and provide the safety alert guarantee for live working staffs, which has very important significance for ensuring the personnel safety of transmission line workers and long-term, safe, stable operation of power transmission line.

\section{System Design}

\subsection{Schematic Diagram}

The core controller of group-type of high voltage electric field measurement and safety distance caution apparatus developed in this paper is C8051F410 single chip microcomputer. The master of whole system device mainly consists of C8051F410 single-chip processing unit, key control unit, voice alarm unit, wireless communication module, LCD liquid crystal display unit, system power supply unit; While the slave is mainly composed of electric field sensor, signal processing circuit unit, C8051F410 single-chip processing unit, key control unit, voice alarm unit, wireless communication module, LCD liquid crystal display unit, system power supply unit. Figure 1 shows the master device.

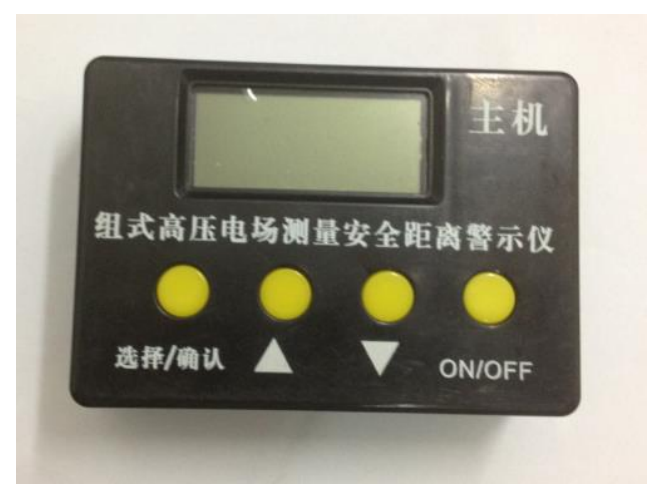

Figure 1. Master Device

The schematic diagram of group-type of high voltage electric field measurement and safety distance caution apparatus is in Figure 2. 


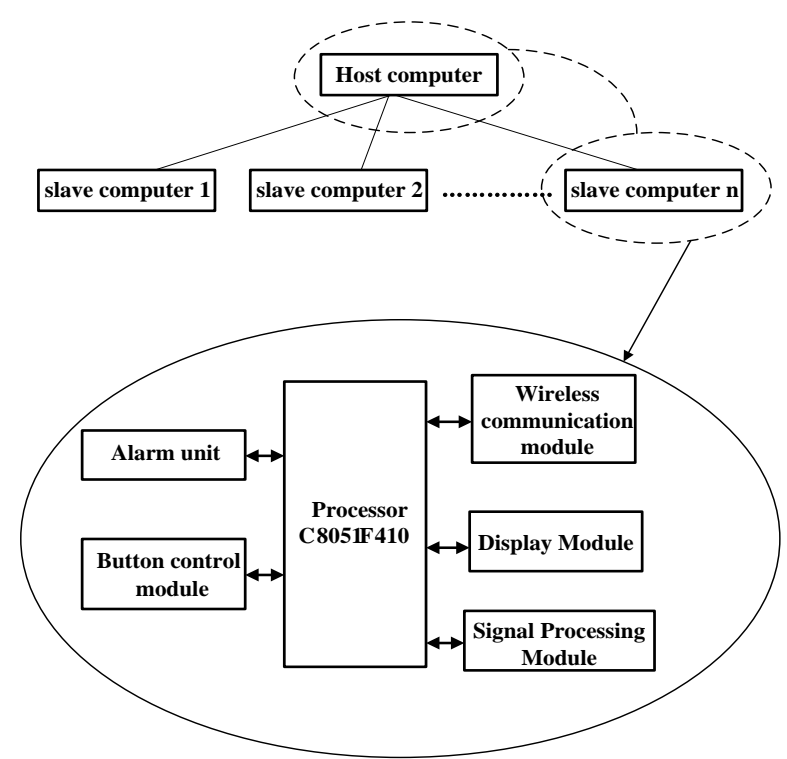

Figure 2. Schematic Diagram

\subsection{Electric Field Sensor}

The function of electric field sensor is receiving signal in power frequency electric field, which has a direct influence on the measurement performance of system. So the design of the sensor must be reasonable. How to ensure that the sensor introduced to measure the electric field without causing significant electric field distortion is the key of sensor design.

In practical engineering applications, we need to choose electric field sensor which has a simple processing and high cost performance, both cylindrical structure electric field sensor and parallel plate structure electric field sensor have these characteristics. Ball structure sensor is very helpful to understand the electric field measurement principle, but the production of it is complex. Literature[7-10] prove that in the uniform electric field and non-uniform electric field environment, compare the ball structure electric field sensor and parallel plate structure electric field sensor, the electric field measurement data difference obtained by those two is very small, even negligible. Therefore, in actual use, the parallel plate structure electric field sensor can meet the measurement accuracy requirements. The design of the parallel plate capacitor electric field sensor in this paper is shown in Figure 3, filling medium inside the sensor with epoxy resin.

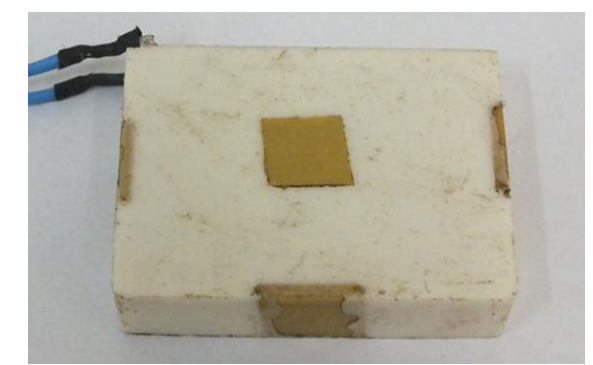

\section{Figure 3. Capacitive Parallel-plate Electric Field Sensor}

In the actual project application, we can use a voltage source model with internal resistance instead of the parallel plate electric field sensor to illustrate its measuring principle[11-15]. Place the measured capacitance CM in the sensor when measuring the 
input signal, to obtain the voltage between the plates by measuring the voltage at the two ends of the measured capacitance CM, the voltage is the input voltage. Regardless of the sensor and the measured capacitance error produced by the internal resistance, the input voltage equivalent circuit of measurement system is shown in Figure 4.

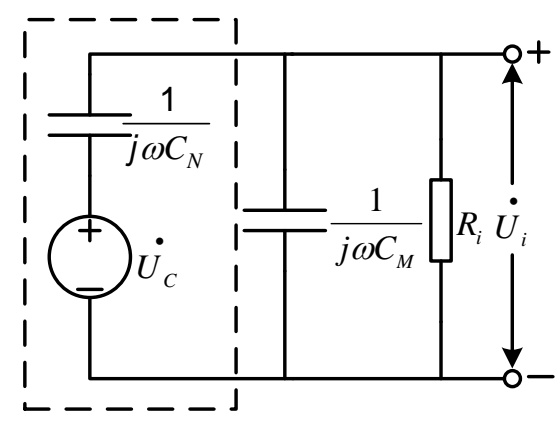

Figure 4. Input Voltage Equivalent Circuit of Measurement System

The size of capacitive parallel-plate electric field sensor is show in Figure 5.

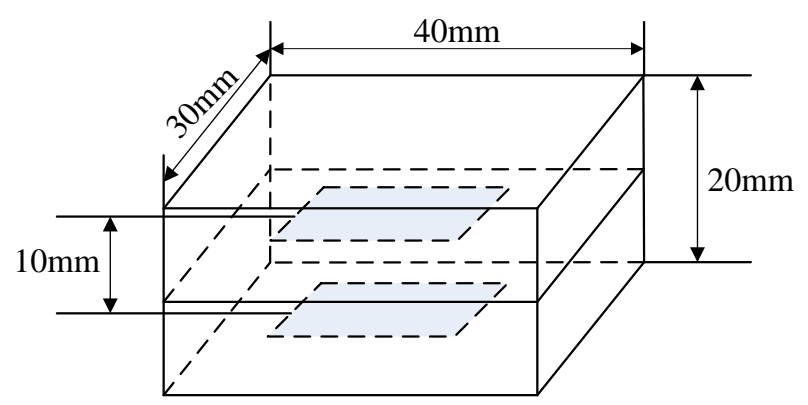

Figure 5. Size of the Sensor

The length is $40 \mathrm{~mm}$, the width is $30 \mathrm{~mm}$, the height is $20 \mathrm{~mm}$, the distance between the two electrode is $10 \mathrm{~mm}$, and the fillers is epoxy resin, its dielectric is $\varepsilon=2.5 \varepsilon 0$, therefore the capacitance of the sensor is shown in the formula (1):

$$
C_{N}=\frac{\varepsilon S}{d} \approx 2.6 p F
$$

For the input voltage equivalent circuit of measurement system in Figure 3, formula (2) can be obtained by calculating:

$$
E_{r m s}=\frac{1}{d \cdot \omega R_{i} C_{N}} \sqrt{\frac{1+\omega^{2} R_{i}^{2} C_{M}^{2}}{2}} U_{i r m s}
$$

then substitute formula (1) into the formula (2):

$$
E_{r m s}=\frac{1}{\varepsilon S \cdot \omega R_{i}} \sqrt{\frac{1+\omega^{2} R_{i}^{2} C_{M}^{2}}{2}} U_{i r m s}
$$

Among which, Erms is the electric field effective value, $S$ is the sensor surface area, $\omega$ is the power frequency voltage angle frequency, $\varepsilon$ is the dielectric constant of epoxy resin, $\mathrm{RI}$ is the input resistor of measurement circuit, $\mathrm{CM}$ is measured capacitance, Uirms is the input voltage effective value. 
From formula (3) we can know, when the other parameters are determined, the electric field intensity of parallel plate sensor location is proportional to the input voltage of measurement system, we only need to measure the input voltage magnitude, then we can get the strength of electric field size where the parallel plate electric field sensor is.

\subsection{Wireless communication module}

The internal of wireless communication module can automatically complete the protocol conversion and data transceiver control, use appropriate serial port to connect the wireless module, allowing the master to inquiry the slaves in turn through the serial port, receive the slave data and send the addressing signal in a certain frequency to each slave, complete the mutual communication between master and slave. The use of wireless communication module brings a benefit that the commanders can monitor the change of electric field intensity at a long distance, which can ensure the personal safety of the operating staffs.

The wireless communication module adopted in this paper is shown in Figure 4 . System uses the UART serial port to connect with the wireless communication module and the half duplex communication between the master and slave system, the baud rate is $9600 \mathrm{bps}$. When the system works, the master will inquiry the slaves in turn through the UART serial port, if the slave receives the inquiry signal, it will transmit the current electric field values and the mark bits of alarm state to the master, The master rolling display each slave's current electric field value, and display the slave number whose current electric field value exceeds the warning value and alarm, in order that the commanders know the staff situation in time.

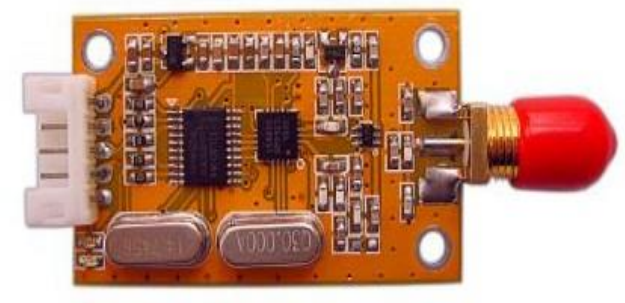

\section{Figure 6. Wireless Communication Module}

\subsection{Signal Processing Module}

The signal processing module includes differential preamplifier circuit, controllable proportional amplifier circuit and third-order Butterworth active filter circuit.

Figure 7 shows the differential preamplifier circuit, we use AD620 to realize the function of differential input, it can restrain common mode interference. The gain of AD620 can be calculate by formula 4:

$$
G_{\mathrm{A}}=\frac{49.4 \mathrm{k} \Omega}{R_{G}}+1
$$




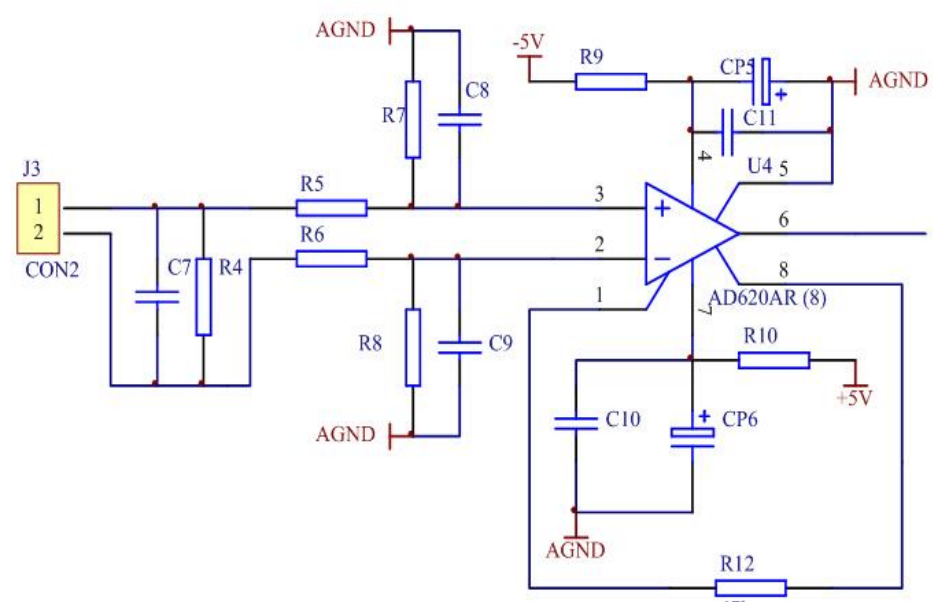

Figure 7. Differential Preamplifier Circuit

Figure 8 shows the controllable proportional amplifier circuit, we use OP07C and ADG1611 to realize the function of proportional amplify.

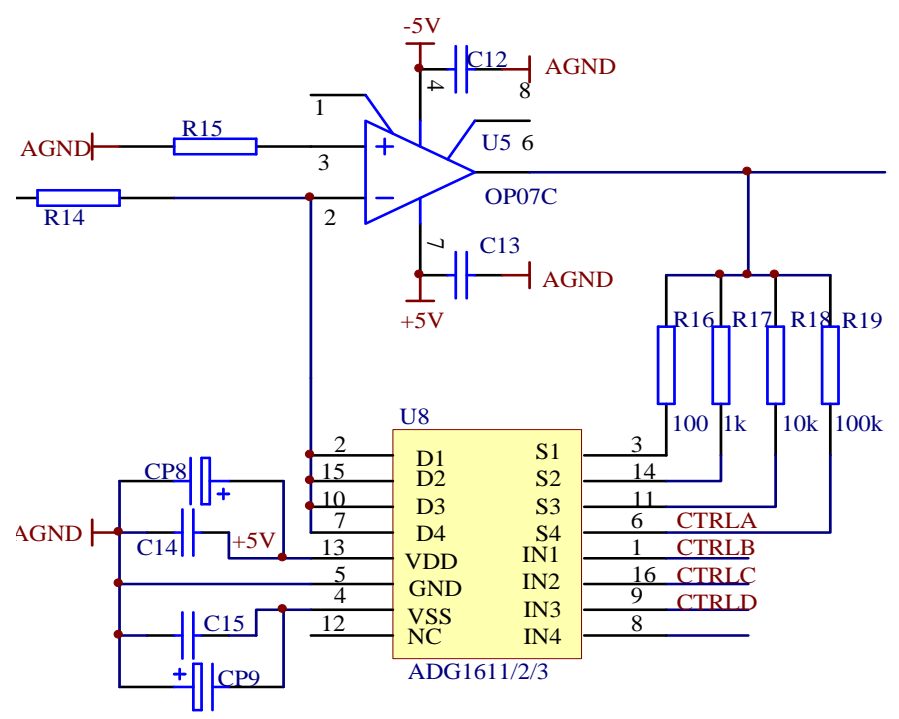

Figure 8. Controllable Proportional Amplifier Circuit

\subsection{The Key Operation and Alarm Tip}

The key control circuit module of the system can realize the startup and shutdown, the selection of different voltage levels and the selection of monitoring different slaves and other functions, The control panel provide 4 keys, the 4 buttons of the master from left to right respectively realize " startup and shutdown ", "successive downturn a number of the slave", "successive upturn a number of the slave" and "selection / confirmation" function, the 4 buttons of the slave from right to left respectively realize " startup and shutdown ", "successive downturn a number of the slave", "successive upturn a number of the slave" and "selection / confirmation" function, among which the "selection / confirmation" button can achieve the selection and confirmation of voltage level or slave number.

The system slaves will have a corresponding alarm value according to different voltage levels. When conducting the transmission line live working at a voltage level, the electric field intensity is lower than the internal limit field system value, it indicates that the workplace field strength meet the standards and workers are safe, the buzzer would not 
call. Once the electric field intensity exceeds the limit, the buzzer alarm immediately to remind workers keep safety distance and prevent the safety accidents.

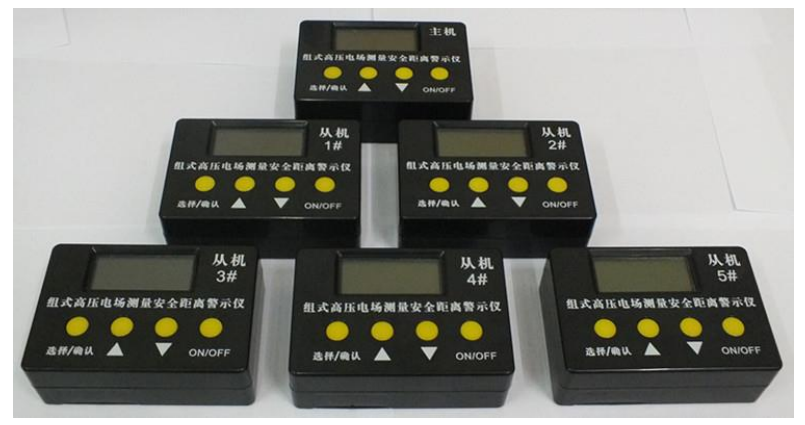

Figure 9. The Group-type of HV Electric Field Measurement Safety Distance Caution Apparatus

Figure 10 shows the PCB board of HV electric field measurement safety distance alarm system.

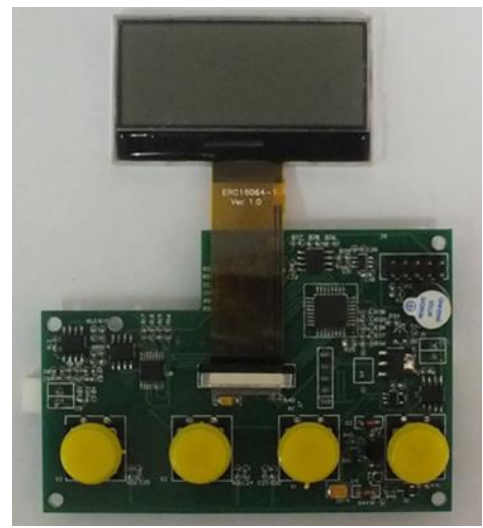

Figure 10. РСB Board

\section{Experimental Research}

In order to inspect the work stability and test accuracy of group-type of high voltage electric field measurement and safety distance caution apparatus under strong electric field environment, conduct a working performance test on the site of Chongqing Rongchang 500kV Hongban transmission line I about the stability and accuracy; In order to inspect the alarm performance and wireless communication performance of the whole system, conduct a test on the site of Chongqing Rongchang 500kV Hongban transmission line I about the working performance of group-type of high voltage electric field measurement and safety distance caution apparatus. Take the measured data of low frequency electromagnetic field measuring instrument EFA300 produced by Germany Narda Company as the reference standard in the experiment. EFA300 is an advanced electromagnetic field measuring instrument ${ }^{[16-18]}$, electric field measurement range is from $0.1 \mathrm{~V} / \mathrm{m}$ to $200 \mathrm{kV} / \mathrm{m}$, equipped with isotropic three-dimensional measurement probe, the probe resolution $0.1 \mathrm{~Hz}$ which possesses a very high accuracy, so we choose the instrument as a reference instrument. 


\subsection{Electric Field Measuring Performance Experiment}

In order to inspect the work stability and measurement accuracy of group-type system slaves, we choose a relatively flat ground between tower $179 \#$ and tower $180 \#$ in Chongqing Rongchang 500kV Hongban transmission line I to conduct electric field measurement. Figure 11 shows the environment of experiment.

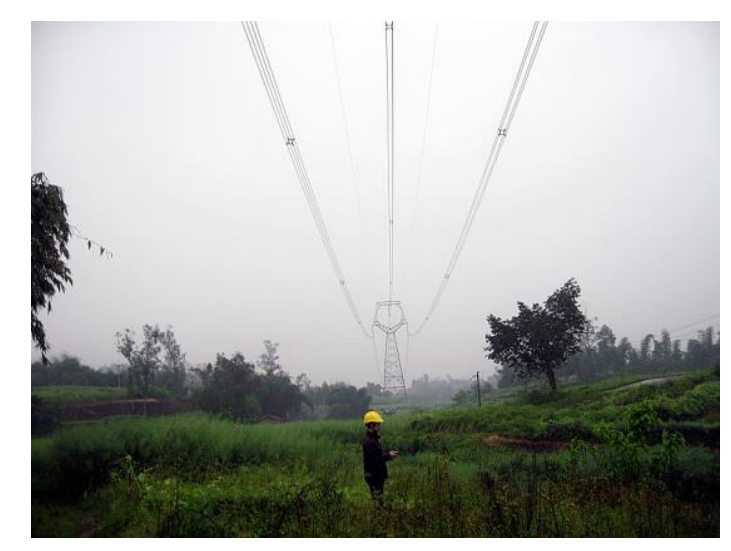

Figure 11. Environment of Experiment

Some basic parameters of the transmission line are: The wire is four bundle conductor, triangular arrangement; middle phase height is $27 \mathrm{~m}$, edge phase height is $23 \mathrm{~m}$; the level interval between edge phase and middle phase is $3 \mathrm{~m}$. The measuring day is cloudy, and the temperature is 21 degrees, relative humidity is $45 \%$. Measuring place is chosen at the central location of the transmission line between the two towers, take the relative projection point of the transmission line central location as measuring coordinate origin, measure along the lateral lines, take one measurement point every $1 \mathrm{~m}$ interval. The measuring point height from the ground is $1.5 \mathrm{~m}$, electric field measurement values of each point must read after waiting the display is basically stable. The comparison chart of the electric field measurement data with EFA300 is shown in Figure 12, its relative error curve is shown in Figure 13.

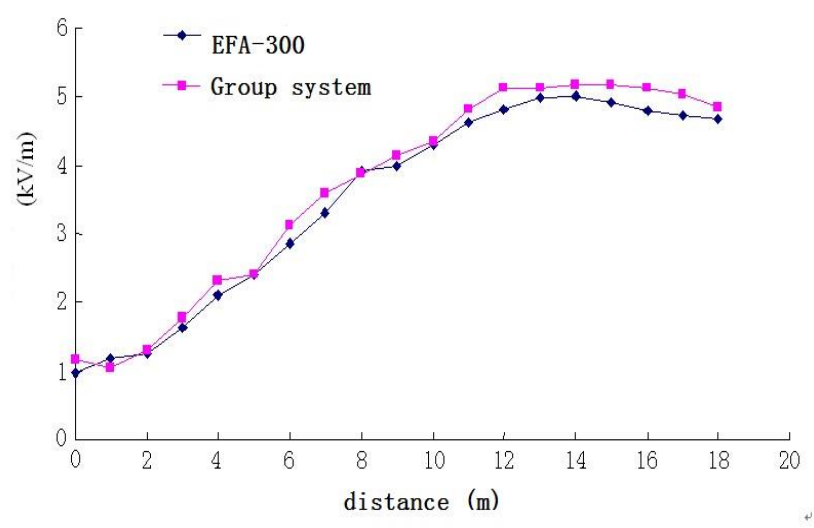

Figure 12. Comparison Chart 


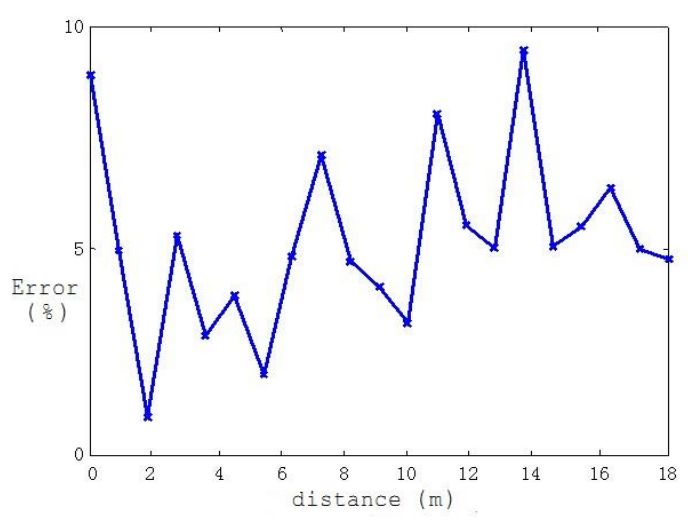

Figure 13. Relative Error Curve

From Figure 12 and Figure 13 we can see, the measurement result distribution trend of group-type system slaves is very close to the measurement result distribution trend of EFA300, the relative error is less than $10 \%$, which indicates that the electric field measurement performance of the group-type system is good and it has high operation stability and measuring accuracy in HV strong electric field environment.

\subsection{Working Performance Experiment of Group-type System Slaves}

We also conduct a test on the site of Chongqing Rongchang 500kV Hongban transmission line I about the working performance of group-type of high voltage electric field measurement and safety distance caution apparatus. This experiment was designed to test alarm performance and wireless communication performance of the group-type system, and the dot-distribution measurement schematic map is shown in Figure 8. Point $1 、 2 、 3$ respectively represent the measuring position of 1 \# slave, point $4,5,6$ respectively represent the measuring position of $2 \#$ slave, point $7 、 8 、 9$ respectively represent the measuring position of $3 \#$ slave, black star represent the master location, among which point $1,2 、 3$ belong to alarm region, while point $2 、 3 、 5 、 6 、 8 、 9$ belong to safe region. Because the minimum height between the transmission line and the ground is $23 \mathrm{~m}$ in practice, which is absolutely safe distance, yet the experiment only test the alarm performance and wireless communication performance of the group-type system, so for convenience, the alarm electric field set value of group-type system at $500 \mathrm{kV}$ voltage level is smaller than the critical electric field simulation value, as $4.5 \mathrm{kV} / \mathrm{m}$, so that it can be divided into alarm region and safe region. Choose arrange three slave computers in their respective location measurement field, when the safety distance than from the machine enters an alarm area, inspection from the machine alarm condition, and to test the effect of the master-slave wireless communication. Arrange 3 slaves measure electric field at location point respectively, when the slave exceeds safety distance and enters alarm region, inspect the alarm condition of the slave and the master-slave wireless communication effect.

The testing distribution method is: first, $1 \#$ slave measures at point 1 in alarm region, 2\# slave measures at point 5 which is close to alarm region but not exceed the safe distance line, $3 \#$ slave measures at point 9 in safe region which is far away from safe distance line; then, $1 \#$ slave measures at point 3 in safe region which is far away from safe distance line, 2\# slave measures at point 4 in alarm region, $3 \#$ slave measures at point 8 which is close to alarm region but not exceed the safe distance line; finally, 1\# slave measures at point 2 which is close to alarm region but not exceed the safe distance line, 2\# slave measures at point 6 in safe region which is far away from safe distance line, $3 \#$ slave measures at point 7 in alarm region. 
From the following 3 tables we can see, group-type system salves can show the electric field intensity of measuring target on the spot and give a notice according to the set voltage grade size. At the same time, the slaves can send the measurement result to the master by means of wireless transmission. When the target measuring points exceed the safety distance in alarm region, the slave will give an audible alarm and send the alarm signal to the master. The experiment result shows: Through the test under $500 \mathrm{kV}$ transmission line, group-type system can work stably in the strong electric field environment, and both the alarm performance and wireless communication performance are very good.

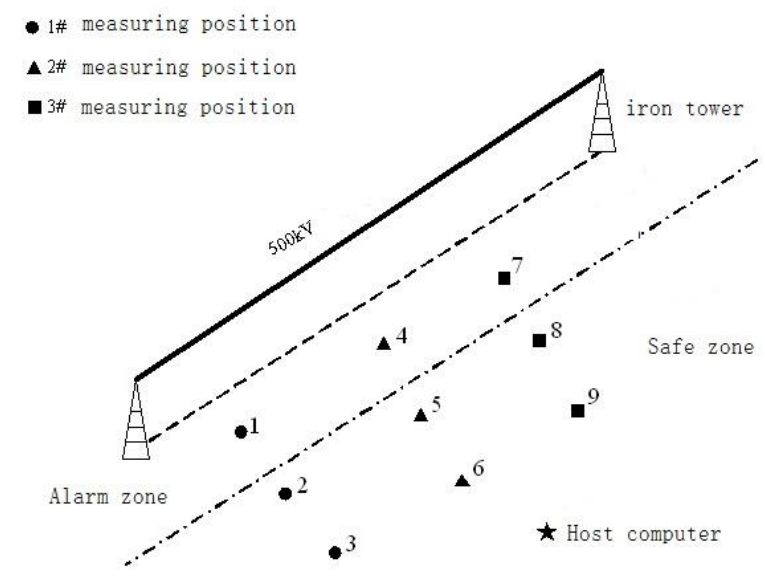

Figure 14. Distribution Measurement Schematic Map for Group-type System under 500kV Transmission Line Site

Table 1. Distribution Measurement Result for Method $1^{\text {st }}$

\begin{tabular}{ccccccc}
\hline & \multicolumn{2}{c}{ Electric field of measuring point $(\mathrm{kV} / \mathrm{m})$} & & Alarm condition of & \multicolumn{2}{c}{$\begin{array}{c}\text { Communication } \\
\text { Slave number }\end{array}$} \\
\cline { 2 - 4 } & 1 & 5 & 9 & slave & condition of master \\
\hline $1 \#$ & 4.784 & - & - & $\sqrt{n}$ & Display and inform \\
$2 \#$ & - & 3.648 & - & $\times$ & Display \\
$3 \#$ & - & - & 2.096 & $\times$ & Display \\
\hline
\end{tabular}

Table 2. Distribution Measurement Result for Method $2^{\text {nd }}$

\begin{tabular}{ccccccc}
\hline & \multicolumn{2}{c}{ Electric field of measuring point $(\mathrm{kV} / \mathrm{m})$} & & Alarm condition of & \multicolumn{2}{c}{$\begin{array}{c}\text { Communication } \\
\text { Slave number }\end{array}$} \\
\cline { 2 - 4 } & 3 & 4 & 8 & slave & condition of master \\
\hline \multirow{2}{*}{$1 \#$} & 2.218 & - & - & $\times$ & Display \\
$2 \#$ & - & 4.975 & - & $\sqrt{n}$ & Display and inform \\
$3 \#$ & - & - & 3.839 & $\times$ & Display \\
\hline
\end{tabular}


Table 3. Distribution Measurement Result for Method $3^{\text {rd }}$

\begin{tabular}{ccccccc}
\hline \multirow{2}{*}{ Slave number } & \multicolumn{2}{l}{ Electric field of measuring point $(\mathrm{kV} / \mathrm{m})$} & Alarm condition of & Communication \\
\cline { 2 - 4 } & 2 & 6 & 7 & slave & condition of master \\
\hline \multirow{2}{*}{$1 \#$} & 3.671 & - & - & $\times$ & Display \\
$2 \#$ & - & 2.561 & - & $\times$ & Display \\
$3 \#$ & - & - & 4.734 & $\sqrt{ }$ & Display and inform \\
\hline
\end{tabular}

\section{Conclusion}

The group-type of high voltage electric field measurement and safety distance caution apparatus is combined with a master and multiple slaves, it can let a group of people use, and the commander monitor the whole group. This electric field measuring device can provide more massive, more detailed and more comprehensive electric field measurement data than that of single type, and the usage method is also more convenient than the single type. The slaves could conduct real-time and effective monitoring of power-frequency electric field near the HV transmission line and directly display the figures. In case of exceeding the safe distance and electric field over-limit, the slaves give an alarm and send the alarming signing to the master. The master keeps the real-time wireless communication with the slaves and conducts the real-time wireless monitoring to the slaves, thus realizing the dual monitoring of site and command and preventing the electric safety accident. Through the test under transmission line, this group-type of high voltage electric field measurement and safety distance caution apparatus can work stably in the strong electric field environment.

\section{Acknowledgements}

This work was supported by the Funding Program from State Grid Chongqing Electric Power CO. Electric Power Research Institute (SGCQDK00JZJS1400018).

\section{References}

[1] Bi T, Shen R, Plans J. A novel method for single phase-to-ground fault location based on wavelet analysis and correlation[C]. Innovative Smart Grid Technologies (ISGT). IEEE, 14(2013)

[2] Barker P P, Mancao R T, Kvaltine D J. Characteristics of lightning surges measured at metal oxide distribution arresters[J]. Power Delivery, IEEE Transactions on, 8(1): 301-310(1993)

[3] John-Paul H.Knauss, Cheri Warren. An Innovative Approach to Smart Automation Testing at National Grid[J]. Transmission and Distribution Conference and Exposition (T\&D), IEEE PES, 1-8(2012)

[4] Liu G Y, Kang L, Peng W N. On-Line Monitoring System for Transformer Partial Discharge[J]. Applied Mechanics and Materials, 303: 464-467(2013)

[5] C.Cecati, C.Citro, P.Siano. Combined Operations of Renewable Energy Systems and Responsive Demand in a Smart Grid[J]. IEEE Transactions on Sust. Energy, Vol.2, N.4:468476(2011)

[6] Kaczkowski A, Knoth W. Combined sensors for current and voltage are ready for application in GIS[J]. CIGRE, 12: 106-108(1998)

[7] Farhangi H. The path of the smart grid[J]. Power and Energy Magazine, IEEE, 8(1): 1828(2010) 
[8] Hou D, Roberts J. Capacitive voltage transformer: transient overreach concerns and solutions for distance relaying[C]. Electrical and Computer Engineering, Canadian Conference on. IEEE, 1: 119-125(1996)

[9] Metwally I A. Coaxial D-dot probe: design and testing[C]. Electrical Insulation and Dielectric Phenomena, 1995. Annual Report, Conference on. IEEE: 298-301(1995)

[10] Baum C, Breen E, Giles. Sensors for electromagnetic pulse measurements both inside and away from nuclear source regions[J]. IEEE Transactions on Antennas and Propagation, 26(1): 22-35(1978)

[11] Browning C A, Vinci S J, Zhu J. An evaluation of electric-field sensors for projectile detection[C]. Sensors, 2013 IEEE: 1-4(2013)

[12] Metwally. I. A. D-dot probe before fast-front voltage measurement. [J]. IEEE Transactions on Instrumentation and Measurement, 59(8):2211-2219(2010)

[13] Haddad A, Naylor P, Metwally I A. An improved non-inductive impulse voltage measurement technique for $\mathrm{ZnO}$ surge arresters[J]. IEEE Transactions on Power Delivery, 10(2): 778-785(1995)

[14] Metwally I A. Comparative measurement of surge arrester residual voltages by D-dot probes and dividers[J]. Electric Power Systems Research,81(7): 1274-1282(2011)

[15] Kubo T, Furukawa T, Fukumoto H. Numerical estimation of characteristics of voltagecurrent sensor of resin molded type for $22 \mathrm{kV}$ power distribution systems[C]. ICCAS-SICE, 2009. IEEE: 5050-5054(2009)

[16] Kubo T, Furukawa T, Itoh H. Numerical electric field analysis of power status sensor observing power distribution system taking into account measurement circuit and apparatus[C]. SICE Annual Conference (SICE), 2011 Proceedings of. IEEE:2741-2746(2011)

[17] Focia R J, Frost C A. A compact, low jitter, $1 \mathrm{kHz}$ pulse repetition rate gas-switched pulse generator system[C]. Pulsed Power Conference, 2005 IEEE. IEEE: 1341-1344(2005)

[18] $\mathrm{Hu}$ Guohu, Chen Hong. Device for measuring $50 \mathrm{~Hz}$ power frequency interference electric field [J]. Medical equipment information, 3: 9-13 (1991)

\section{Authors}

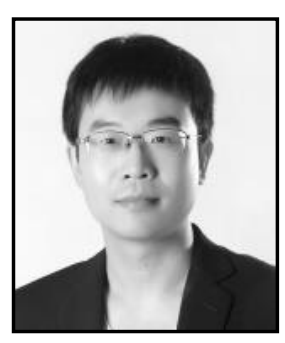

Qiang Zhou, $\mathrm{Ph}$.D. degree, his main research interest is numerical calculation of the electromagnetic field and electric power measurement.

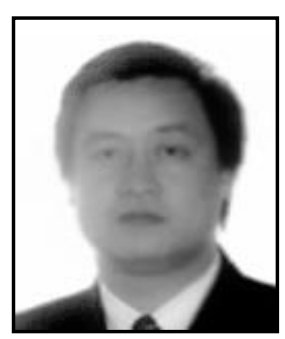

Wei He, He received the Ph.D. degrees in electrical engineering from Hamburg University of Technology, in 1997. His main fields of interest are numerical calculation, power system fault diagnosis and electromagnetic compatibility. 